\title{
Development and Effects of Supplementary Textbook about EKG for Nursing Students
}

\author{
Yeom, Gye Jeong ${ }^{1)} \cdot$ Yang, Jeongha $^{2)(} \cdot$ Kim, Hyun Sook ${ }^{3)}$
}

\author{
1) Assistant Professor, Department of Nursing, JEI University, Incheon \\ 2) Associate Professor, Department of Nursing, JEI University, Incheon \\ 3) Assistant Professor, Department of Nursing, Gangdong University, Eumseong, Korea
}

\begin{abstract}
Purpose: The aim of this study was to develop teaching material of electrocardiography (ECG) education for nursing students. Teaching material was designed to increase ECG knowledge and self-confidence of nursing students. Methods: A convenience sample of 72 nursing students in a university of South Korea were recruited to an experimental group $(n=36)$ or a control group $(n=36)$. A non-equivalent control group pretest-posttest design was employed to test effects of teach material on ECG knowledge and self-confidence of nursing students. Teaching material was developed based on analysis learners, state objectives, select media \& materials, utilize media \& materials, require learner participation, and evaluate \& revise (ASSURE) model. ECG knowledge and self-confidence were self-reported using scales developed by authors. Pre-test and post-test data were collected before and after a three-week intervention period. Results: The ECG knowledge of the experimental group was significantly higher than that of the control group $(\mathrm{t}=6.86, p<.001)$. And the self-confidence of the experimental group was significantly higher than that of the control group $(t=3.07, p=.003)$. Conclusion: Teaching material developed in this study was effective in improving ECG knowledge and self-confidence of nursing students. Thus, this teaching material could be used as supplementary textbook in diverse nursing practice education such as simulation or nursing skill training.
\end{abstract}

Key Words: Teaching material; Electrocardiography; Nursing, Students

Received Feb 18, 2020 Revised Apr 29, 2020 Accepted Aug 6, 2020

Corresponding author: Yang, Jeongha https://orcid.org/0000-0001-5454-8440

Department of Nursing, JEI University

178 Jaeneung-ro, Dong-gu, Incheon 22573, Korea

Tel: +82-32-890-7322, Fax: +82-32-890-7199, E-mail: jhyang@jeiu.ac.kr 


\section{INTRODUCTION}

Electrocardiography (ECG) is a device that monitors dysrhythmia or cardiovascular abnormalities by attaching to the chest and limbs and reading a graph of the cardiac rhythm, patterns, and electrical axis. It could be used to detect coronary artery diseases or dysrhythmia and treat them quickly and accurately [1]. ECG is a non-invasive test method. Because it is not dangerous to the subject, it is widely used in clinical settings such as intensive care units, emergency rooms, and operating rooms, as well as in internal medicine field [2]. To treat and care for patients with cardiovascular abnormalities, medical staff needs knowledge acquisition and performance related to ECG [3]. In particular, intensive care unit nurses should have professional understanding and ECG knowledge to detect early myocardial infarction or dysrhythmia that requires immediate intervention [4].

The Korean nurses association's learning objectives for the education of nursing students related to ECG are as follows: assess cardiac tissue perfusion disorders; plan nursing goals and interventions related to cardiac tissue perfusion disorders; and implement nursing intervention and evaluate cardiac tissue perfusion disorders [5]. Nursing students are expected to be able to identify health problems and nursing needs related to coronary artery disease and dysrhythmia, and to apply the nursing process. However, unlike the increasing number of nursing colleges, clinical practice is being focused on observation rather than performance. Practical education environment is becoming worse due to the lack of departments such as intensive care units, emergency rooms, and operating rooms [6]. Therefore, it is not possible for students to have enough training on attachment an interpretation of ECG at the cardiovascular ward or intensive care unit. Thus, students must acquire the relevant preliminary knowledge prior to practice. Textbooks, guidelines, or handbooks that are currently used for ECG education contain a wide range of basic information, including cardiovascular diagnostic tests, normal sinus rhythm, characteristics of dysrhythmia [7-12]. However, there remains a need to systematically develop textbooks to reflect the needs of nursing students.

We will apply the ASSURE model as a system design model that was planned, reviewed, and implemented systematically [13] to develop ECG textbooks that could be used more effectively in practice. The ASSURE model has six steps: analyze learners, state objectives, select media \& materials, utilize media \& materials, require learner participation, and revaluate \& revise. In general, a textbook refers to a printed material that systematically presents educational objectives and details of education so that the learner can reach them. A supplementary textbook is one that reflects the needs of learners and complements the content of main textbooks [14]. The textbook to be developed in this study are at a level that helps students who have difficulty in understanding abstract concepts due to lack of practical experience. If students use supplementary textbooks to induce deepening or self-directed learning in difficult areas, the effect of nursing education will be increased.

The purpose of this study is to develop ECG textbook and verify effects in improving ECG knowledge and selfconfidence of nursing students. The hypothesis of this study are as follows.

- Hypothesis 1. The experimental group with developed ECG textbook will have a higher level of ECG knowledge than the control group.

- Hypothesis 2. The experimental group with developed ECG textbook will have higher self-confidence level than the control group.

\section{METHODS}

\section{Study Design}

This study was a Quasi-experimental design and nonequivalent comparison group before/ after time-series design to verify the effect of ECG textbook developed for nursing students.

\section{Participants}

Subjects of this study were students of a nursing college who took a course in the 'Adult Healthy Nursing' curriculum including theory about cardiac disease and dysrhythmia. Students in the 3rd grade who were scheduled to practice cardiovascular ward were recruited. Study participants had not conducted clinical practice before. The effect size was set to .80 based on results of a previous study [15] to set the target subject population, the sample size of the study. Using $G^{*}$ power program 3.1.9 and with a power (1B) of .90 , a significant level of .05 , an effect size of .80 , and two-tailed independent t-test resulted in a sample size of 34 people per group. Initially, a total of 73 people participated. However, one subject in the control group did not respond to the follow-up. Therefore, 36 subjects in the experimental group and 36 subjects in the control group were included in the final analysis (Figure 1). 


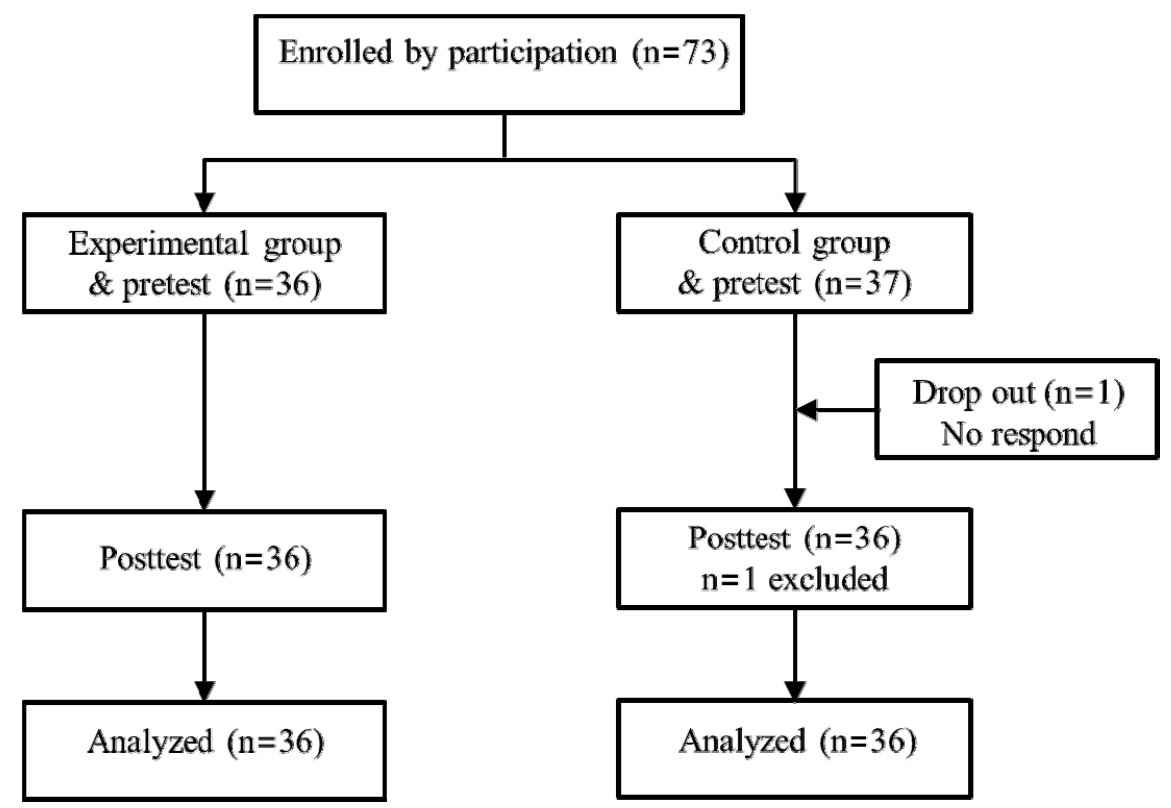

Figure 1. Flow diagram of the study participants.

\section{Development Procedure}

The instructional systems design (ISD) used to develop the textbook was an ASSURE model.

\section{1) Analysis of learners}

To examine the ECG learning starting ability and learning preference, 78 fourth graders who had already completed the practice of circulatory adult nursing theory and cardiovascular ward a year ago were surveyed with semistructured questions. In response to the following survey question, 'What was the most difficult part of the circulatory adult nursing theory classes?' 46 (59.0\%) students responded with interpretation of ECG, 19 (24.4\%) responded with cardiac disease, 11 (14.1\%) responded with cardiac pathophysiology, and $2(2.5 \%)$ responded with cardiac rehabilitation. As for the reason why students' interpretation of ECG was so low, the most common reason was 'unfamiliar' (57.7\%), followed by 'the lack of effective learning method' (37.2\%). In response to the question of 'What was the most beneficial nursing skill in cardiovascular ward?' 34 (37.8\%) students responded with auscultation, $26(28.9 \%)$ responded with ECG, 16 (17.8\%) responded with cardiovascular angiography, and 14 (15.5\%) responded with central venous pressure. When they are asked 'How would you like to develop ECG self-study material for nursing students?' 38 (48.7\%) students responded with booklet-type textbook, 19 (24.4\%) responded with practice guideline, and 17 (21.8\%) responded with mobile-based material.

\section{2) State objectives}

As a result of analyzing ECG-related studies by searching literatures, the educational purpose of this textbook was 'to get relevant knowledge and self-confidence through sufficient understanding of the ECG'. Detailed goals to achieve this purpose were selected as follows: 'Describe the purpose of ECG monitoring (understanding)', 'Attach ECG monitor electrodes accurately (application)', 'Interpret waves from ECG monitors (understanding)', and 'Plan nursing interventions with priorities for dysrhythmia (application).'

\section{3) Select media \& develop materials}

Nursing students are not able to easily use a computer or a mobile phone in a clinical practice site. Given this reality, booklet-type textbook that can be used immediately anywhere (at school, at home, or in practice) will to be useful. Even in the preceding stage of learners' analysis, students preferred print media. Therefore, it was set up as a textbook in the form of printed materials to effectively deliver images and text. As a result of analyzing adult nursing textbooks and ECG-related books, there was a need to recreate data highlighting graph images and characteristics of normal and abnormal waves so that nursing students could understand them. To develop such materials, we first selected the main topic and sub-topic and composed a storyboard based on these topics. To produce images, we utilized SimMan 3G ECG screen images of Laerdal $^{\mathrm{TM}}$ products in the nursing lab of our college and obtained the usage consent of the manufacturer. Standard- 
ized terms and contents were derived by referring to adult nursing books and data related to ECG and cardiovascular first aid $[8,16]$.

As a strategy to increase the attractiveness of this textbook and to stimulate learning, data were developed by applying the attention, relevance, self-confidence, satisfaction (ARCS) model [17]. To attract learners' attention, we developed fonts and colors suitable for college students' senses and used a friendly visual design. By adopting flat design familiar to young students, comfortable layout was created so that students could naturally follow things divided into blocks. Color also follows the same color so that related contents will appear. As a content relevance promotion strategy, various ECG waveforms were taken and utilized from a laptop screen connected to a high-fidelity simulator in the college, enabling students to learn from familiar images. As a strategy to improve the self-confidence of learners, normal wave was fully learned first. The level of difficulty was then adjusted to learn abnormal waves. Only one wave was presented on a single page so that students could find it easily. The plan was to limit the total amount to around 30 pages to include only necessary information. To increase learner satisfaction, self-tests and answers were presented at the end so that continuous learning enhancement and feedback could be obtained. Contents and details of the textbook developed in this study are shown in Table 1.

Table 1. Contents of Supplementary Textbook for ECG

\begin{tabular}{|c|c|}
\hline Contents & Details \\
\hline Attaching ECG & $\begin{array}{l}\text { The 12-Lead ECG } \\
\text { ECG monitor }\end{array}$ \\
\hline $\begin{array}{l}\text { Calculating } \\
\text { heart rate }\end{array}$ & \\
\hline $\begin{array}{l}\text { Drawing a } \\
\text { normal wave }\end{array}$ & \\
\hline $\begin{array}{l}\text { Characteristics } \\
\text { of abnormal } \\
\text { waves, } \\
\text { symptoms \& } \\
\text { nursing }\end{array}$ & $\begin{array}{l}\text { Ventricular fibrillation } \\
\text { Ventricular tachycardia } \\
\text { Complete AV-block } \\
\text { Atrial fibrillation } \\
\text { Atrial flutter } \\
\text { Paroxysmal supra ventricular tachycardia } \\
\text { Premature ventricular contraction } \\
\text { Junctional rhythm } \\
\text { Sinus bradycardia } \\
\text { Sinus tachycardia } \\
\text { Myocardial infarction } \\
\text { Hyperkalemia }\end{array}$ \\
\hline $\begin{array}{l}\text { Repetition and } \\
\text { self-evaluation }\end{array}$ & $\begin{array}{l}\text { First test with hint } \\
\text { Second test without hint }\end{array}$ \\
\hline
\end{tabular}

ECG=electrocardiogram.

\section{4) Utilize media \& materials}

After the textbook draft was completed, five experts (one cardiologist, one cardiovascular specialist nurse, and three professors in adult nursing) evaluated content validity. They recommended that study contents are organized based on symptoms and immediate nursing, rather than the cause of abnormal waves, and emergency drugs frequently used are exemplified. Opinions of experts were actively reflected. Formative evaluation was conducted from 20 fourth grade students. They suggested that the amount and difficulty of the textbook should be adjusted to understand. Based on the evaluation results, some contents of the textbook were deleted and modified by limiting the number of types from 20 to 12 , mainly for abnormal waveforms that would require immediate nursing care. And a page was added to allow the learner to fully learn and directly draw the normal waves. To enhance the understanding with aesthetic effect, both the cover and text of the textbook were printed in color and prepared in pocket book size (A5) (Figure 2).

\section{5) Require learner participation}

After introducing various waves-specific images and features, a self-test was performed at the end and the difficulty of the test was adjusted by providing hints with cardiac conduction system images.

\section{6) Revaluate \& revise}

To evaluate the learner satisfaction, 36 subjects were surveyed for learner satisfaction with eight questions immediately after the end of the 3-week intervention period. Satisfaction with the teaching method using the developed textbook had an average score of 4.53 points (out of 5 points). The reason for this high score was because the textbook contained a lot of figures which helped them understand ECG. Satisfaction with the volume of textbook had 4.53 points, indicating that the textbook was appropriate for students to understand. Their satisfaction with the editorial design had 4.34 points, meaning that the editorial design helped them show interest in learning. In addition, the response to whether it helped them practice in cardiovascular ward had 4.06 points. The most beneficial parts were reading abnormal waves $(37.5 \%)$, drawing normal waves (34.4\%), implementing nursing $(15.6 \%)$, calculating cardiac rate $(9.4 \%)$, and attaching ECG $(3.1 \%)$.

\section{Measures}

\section{1) Knowledge of ECG}

To evaluate whether learners reached their educational 


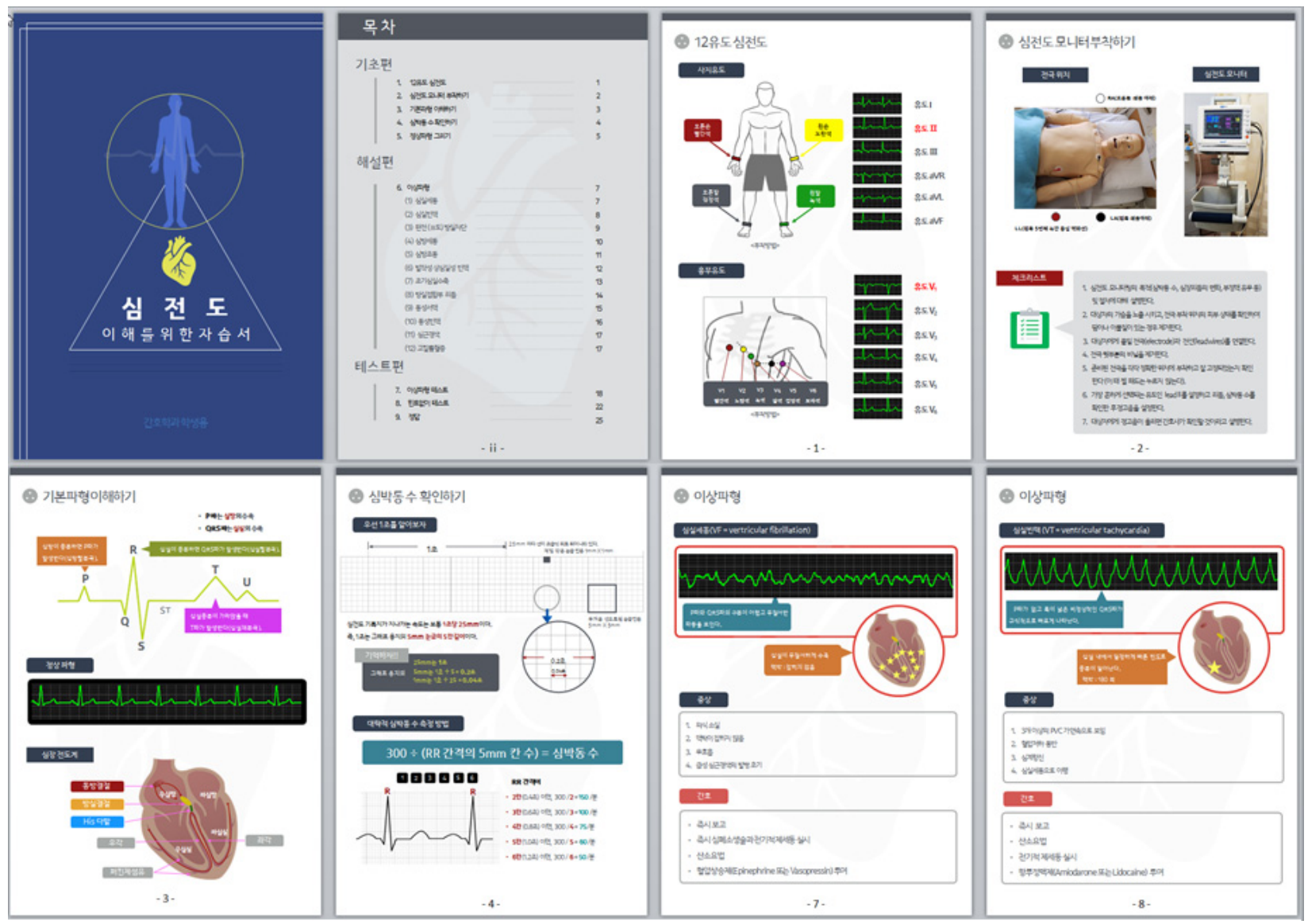

Figure 2. Teaching material for ECG.

goals, we developed an ECG knowledge scale that was verified by one cardiovascular specialist nurse and two adult nursing professors. All items were accepted as a result of verifying the item-content validity index (I-CVI) with Likert 4-point scale of .80 or more [18]. All questions were 5-point multiple choice as the type of Korean nurses licensing examination. Of a total of 20 questions, 4 questions were about characteristics of normal wave, 9 questions were about characteristics of abnormal waves, and the remaining 7 questions were visual presentation questions, in which waves were presented graphically. A correct answer was scored 1 point while a wrong answer was scored 0 point. The total score ranged from 0 to 20 points, with a higher score indicating a higher degree of ECG knowledge. The reliability value of this scale was analyzed by Kuder-Richardson 20 (KR20) to be 83 .

\section{2) Self-confidence}

The self-confidence scale developed a total of 10 questions to measure the self-confidence in nursing performance for dysrhythmia. The content validity was verified by one cardiovascular specialist nurse and two adult nursing professors and all items were accepted as a result of verifying the I-CVI with Likert 4-point scale of .80 or more [18]. These questions composed of 'Can describe the purpose of ECG monitoring (understanding)', 'Can see and interpret the waves of ECG monitor (understanding)', 'Can attach ECG electrode correctly (application)', 'Can plan nursing intervention considering priority for dysrhythmia (application)'. There questions were divided into two categories: 6 questions for self-confidence in understanding ECG and 4 questions for self-confidence in applying nursing practice. All items were scored on a scale of 0 to 10 (very confident $=10$ points, no self-confidence at all $=0$ point), with higher score indicate higher level of nursing practice selfconfidence for dysrhythmia. The reliability value of this scale was analyzed by Cronbach's $\alpha$ which was .93 .

\section{Data Collection}

The period of data collection was from April 29, 2019 to June 21, 2019. This study was conducted with the approval of the Institutional Review Board of the University in Seoul to protect the ethical aspects of study subjects (2- 
7001793-AB-N-012019018HR). Voluntary participation, anonymity guarantee, possibility of withdrawal, disadvantage, and harmlessness were specified and consent was obtained in writing after describing these to all participants. The control group was also informed to provide the ECG textbook developed immediately after the experiment was completed. Since all interventions and investigations were for study purpose only, we explained that they would not be applied to class or practice evaluations. In order to control exogenous variables called practical experience, this study was conducted for 3rd grade students who first started clinical practice. Also, the two groups were placed in the same hospital and department every 3 weeks. 10 sets of 5 to 8 people each were divided into 5 sets of experimental groups and 5 sets of control groups to prevent the spread of experimental effects among groups that could occur during the practice period. The period of each group's practice in the cardiovascular ward was 3 weeks for a total of 6 weeks. The control group of students participated in the study for the first 3 weeks and the experimental group of students were given the material for the second 3 weeks so that the control group was not exposed to the intervention material. The study assistant who helped distribute the questionnaire for the survey did not know which group the subject belonged to. For the intervention, researchers handed out the developed textbooks to the experimental group, allowed them self-learning in a classroom of the college for one hour, and then use in home or practice hospitals for 3 weeks. On the other hand, the control group was instructed to do self-study centering on the main textbook and practice guide. Both groups were followed up on the last day of the 3-week cardiovascular ward practice. After the follow-up investigation, the control group was provided with the developed textbook.

\section{Data Analysis}

Collected data were analyzed using the SPSS/WIN 21.0 program. The dependent variables and the general characteristics of the subjects were analyzed using descriptive statistics. Differences between the experimental group and the control group were analyzed by independent t-test to verify prior homogeneity and hypothesis.

\section{RESULTS}

\section{Homogeneities between Experimental Group and Control Group}

Regarding the general characteristics of study subjects, there were 16 males and 56 females. All of subject was $23.75 \pm 4.58$ years old $(t=0.77, p=.444)$. As a result of confirming the adult nursing grade score before the study, homogeneity was secured between the two groups $(\mathrm{t}=1.71$, $p=.092)$. As a result of comparing prior knowledge $(t=1.33$, $p=.189)$ and prior self-confidence $(\mathrm{t}=0.10, p=.918)$ between the two groups, there was no significant difference in total scores. However, there was a difference in visual presentation items of prior knowledge $(\mathrm{t}=2.51, p=.014)$. These results are summarized in Table 2.

\section{Testing of Hypothesis}

As a result of analyzing the collected data to test hypothesis 1 , the control group's knowledge difference between after and before score was $-0.22 \pm 2.50$ and the experimental group's knowledge difference between after and before score was $4.89 \pm 3.99$. As a result of testing differences between the two groups, the average score of the experimental group was significantly higher than that of the control group $(t=6.51, p<.001)$. Among knowledge

Table 2. Homogeneity Test between Experimental and Control Groups

$(N=72)$

\begin{tabular}{|c|c|c|c|c|}
\hline Variables (possible range) & Exp. $(n=36)$ & Cont. $(n=36)$ & $\mathrm{t}$ & $p$ \\
\hline Age (year) & $24.17 \pm 5.35$ & $23.33 \pm 3.67$ & 0.77 & .444 \\
\hline Adult nursing grade score $(0 \sim 100)$ & $85.97 \pm 6.00$ & $82.75 \pm 9.55$ & 1.71 & .092 \\
\hline $\begin{array}{l}\text { ECG knowledge }(0 \sim 20) \\
\text { Characteristics of normal wave }(0 \sim 4) \\
\text { Characteristics of abnormal waves }(0 \sim 9) \\
\text { Visual presentation }(0 \sim 7)\end{array}$ & $\begin{array}{l}8.72 \pm 2.46 \\
2.25 \pm 1.16 \\
3.83 \pm 1.54 \\
2.64 \pm 1.31\end{array}$ & $\begin{array}{l}8.00 \pm 2.15 \\
2.47 \pm 0.74 \\
3.67 \pm 1.47 \\
1.86 \pm 1.31\end{array}$ & $\begin{array}{r}1.33 \\
-0.97 \\
0.47 \\
2.51\end{array}$ & $\begin{array}{l}.189 \\
.334 \\
.640 \\
.014\end{array}$ \\
\hline $\begin{array}{l}\text { Self-confidence }(0 \sim 100) \\
\text { Understanding ECG }(0 \sim 60) \\
\text { Applying nursing practice }(0 \sim 40)\end{array}$ & $\begin{array}{l}33.67 \pm 17.09 \\
20.67 \pm 11.27 \\
13.00 \pm 7.02\end{array}$ & $\begin{array}{l}33.22 \pm 19.20 \\
18.72 \pm 12.07 \\
14.50 \pm 8.32\end{array}$ & $\begin{array}{r}0.10 \\
0.71 \\
-0.83\end{array}$ & $\begin{array}{l}.918 \\
.482 \\
.411\end{array}$ \\
\hline
\end{tabular}

Cont. =control group; $\mathrm{ECG}=$ electrocardiogram; Exp.=experimental group. 
Table 3. Comparison of ECG Knowledge and Self-Confidence between Experimental and Control Groups

$(N=72)$

\begin{tabular}{|c|c|c|c|c|c|c|}
\hline \multirow[t]{2}{*}{ Variables (possible range) } & \multirow[t]{2}{*}{ Groups } & Before & After & \multirow[t]{2}{*}{$\mathrm{t}(p)$} & $\begin{array}{c}\text { Difference } \\
\text { (After-Before) }\end{array}$ & \multirow[t]{2}{*}{$\mathrm{t}(p)$} \\
\hline & & $\mathrm{M} \pm \mathrm{SD}$ & $\mathrm{M} \pm \mathrm{SD}$ & & $\mathrm{M} \pm \mathrm{SD}$ & \\
\hline \multirow[t]{2}{*}{ ECG knowledge (0 20) } & Exp. $(n=36)$ & $8.72 \pm 2.46$ & $13.61 \pm 4.33$ & 6.86 & $4.89 \pm 3.99$ & 6.51 \\
\hline & Cont. $(n=36)$ & $8.00 \pm 2.15$ & $7.78 \pm 2.70$ & $(<.001)$ & $-0.22 \pm 2.50$ & $(<.001)$ \\
\hline \multirow[t]{2}{*}{ Characteristics of normal wave $(0 \sim 4)$} & Exp. $(n=36)$ & $2.25 \pm 1.16$ & $3.25 \pm 0.81$ & 4.38 & $1.00 \pm 1.39$ & 3.88 \\
\hline & Cont. $(n=36)$ & $2.47 \pm 0.74$ & $2.28 \pm 1.06$ & $(<.001)$ & $-0.19 \pm 1.21$ & $(<.001)$ \\
\hline \multirow{2}{*}{ Characteristics of abnormal waves $(0 \sim 9)$} & Exp. $(n=36)$ & $3.83 \pm 1.54$ & $5.28 \pm 2.53$ & 4.15 & $1.44 \pm 2.10$ & 4.14 \\
\hline & Cont. $(n=36)$ & $3.67 \pm 1.47$ & $3.31 \pm 1.33$ & $(<.001)$ & $-0.36 \pm 1.55$ & $(<.001)$ \\
\hline \multirow[t]{2}{*}{ Visual presentation $(0 \sim 7)$} & Exp. $(n=36)$ & $2.64 \pm 1.31$ & $5.08 \pm 1.57$ & 8.20 & $2.44 \pm 1.99$ & 5.04 \\
\hline & Cont. $(n=36)$ & $1.86 \pm 1.31$ & $2.19 \pm 1.41$ & $(<.001)$ & $0.33 \pm 1.53$ & $(<.001)$ \\
\hline \multirow[t]{2}{*}{ Self-confidence $(0 \sim 100)$} & Exp. $(n=36)$ & $33.67 \pm 17.09$ & $52.69 \pm 17.98$ & 3.07 & $19.03 \pm 20.33$ & 2.78 \\
\hline & Cont. $(n=36)$ & $33.22 \pm 19.20$ & $39.64 \pm 18.11$ & $(.003)$ & $6.42 \pm 18.13$ & $(.007)$ \\
\hline \multirow[t]{2}{*}{ Understanding ECG (0 60) } & Exp. $(n=36)$ & $20.67 \pm 11.27$ & $32.14 \pm 11.26$ & 2.90 & $11.47 \pm 14.02$ & 2.11 \\
\hline & Cont. $(n=36)$ & $18.72 \pm 12.07$ & $24.03 \pm 12.42$ & $(.005)$ & $5.31 \pm 10.54$ & $(.039)$ \\
\hline \multirow[t]{2}{*}{ Applying nursing practice $(0 \sim 40)$} & Exp. $(n=36)$ & $13.00 \pm 7.02$ & $20.56 \pm 7.88$ & 2.93 & $7.56 \pm 8.23$ & 3.29 \\
\hline & Cont. $(n=36)$ & $14.50 \pm 8.32$ & $15.61 \pm 6.38$ & $(.005)$ & $1.11 \pm 8.41$ & $(.002)$ \\
\hline
\end{tabular}

Cont.=control group; ECG=electrocardiogram; Exp.=experimental group.

questions, characteristics of normal wave $(\mathrm{t}=3.88, p<.001)$, characteristics of abnormal waves $(\mathrm{t}=4.14, p<.001)$ and visual presentation $(t=5.04, p<.001)$ were significantly higher in the experimental group (Table 3). Thus, Hypothesis 1 was supported.

As a result of analyzing the collected data to test hypothesis 2, the self-confidence difference between after and before score of the control group was $6.42 \pm 18.13$ and that of the experimental group was $19.03 \pm 20.33$. As a result of testing differences between the two groups, the average value of the experimental group was significantly higher than that of the control group ( $\mathrm{t}=2.78, p=.007)$. Among selfconfidence questions, understanding ECG $(\mathrm{t}=2.11, p=.039)$ and applying nursing practice $(t=3.29, p=.002)$ were both significantly higher in the experimental group (Table 3 ). Thus, Hypothesis 2 was supported.

\section{DISCUSSION}

This study developed textbooks for enhancing ECG knowledge and self-confidence of nursing students before practicing in cardiovascular ward and verified the application effect. The development process was systematically conducted according to the ASSURE model teaching design to meet the needs and levels of learners. Thus, the difficulty level was adjusted to reflect students' opinions through a formative evaluation and a textbook was developed in the form of a booklet that students preferred. Contents and compositions of the textbook emphasized
ECG waves and the principle visually to improve their understanding and repeated learning through self-tests. In particular, it was revealed that the ECG waveform from the laptop screen connected to a high-fidelity simulator in the college was different from that shown in existing textbooks. Thus, students need to learn from a familiar image.

As a result of verifying the effect of the textbook, the experimental group subjects who learned from the developed textbook showed a significant difference in ECG knowledge score compared to subjects in the control group. This result suggested that, although both groups of subjects took the same circulatory adult nursing theory before intervention and had experience in cardiovascular ward practice, there was a difference in knowledge between the two groups due to the educational effect of the textbook. The proper placement of the waveforms and the cardiac conduction system image shown in the textbook might have improved their knowledge by increasing their interest in learning [13]. In a previous study, 8 weeks of theoretical and practical training for emergency rescue workers has shown the pre-education knowledge accuracy rate increased $18.5 \%$ (from $26.8 \%$ to $45.3 \%$ ) after education [19]. In this study, knowledge of the experimental group improved after intervention, showing an increase of $24.4 \%$. Therefore, if students who need reinforcements in understanding and interpreting ECGs during adult nursing courses use this textbook to provide in-depth education, effective education performance will be achieved. If nursing students use well-developed textbooks and study 
well, they obtain more effective educational achievement during practice training [15].

Results of this study showed that self-confidence scores of subjects in the experimental group who learned from the developed textbook were significantly higher than those of the control group. Self-confidence means the belief that can do something and the state of mind that want to do it successfully for the desired result [20]. Learning goals presented in this textbook were selected according to levels of learners. Students were able to learn enough and gain self-confidence as the result of adjusting the amount of learning to 12 waves by selecting only learning contents that students should know. Previous studies that applied e-learning and peer learning to ECG education have shown that self-confidence is increased from $30 \%$ to $60 \%$ [21]. The experimental group's self-confidence was increased in this study. Improving students' self-confidence is important not only in nursing education, but also in practice. A previous research has shown that new nurses who have high satisfaction with clinical practice as students are well adapted to their practice with little turnover [22]. Pocket-sized textbooks are easy to carry so that students can learn materials anywhere, anytime. In addition, visual design fitting students' sense is an attractive teaching material [15]. Therefore, if students are encouraged to improve self-directed learning by utilizing supplementary textbooks for areas where they are difficult, the effect of nursing education will be increased as a result. The limitation of this study was that although exogenous variables were controlled by conducting a pre- and post-examination of the control group, the study was conducted with students from a single college. Therefore, caution is needed when generalizing results of this study.

\section{CONCLUSION}

This study developed an ECG textbook for nursing students based on systematic teaching design and its effectiveness was verified. For the development of the textbook, levels of learners were analyzed and a learner-centered design process was applied. After providing the textbook and verifying its effect, the experimental group showed higher ECG knowledge and self-confidence than the control group. Therefore, this textbook can be used to effectively increase the self-confidence and prior knowledge of students ahead of clinical practice. It can also be used to reflect changes in learners' needs and the educational environment so that it can be developed into an editable textbook. Regarding suggestions for further studies, first, it is necessary to conduct a textbook effectiveness ver- ification for nursing students located in various regions. Second, it is necessary to improve the learning effect and satisfaction by repeatedly applying, evaluating, and revising the textbook of this study. Third, since practice-related skills have been emphasized in the nursing curriculum recently, we propose that this textbook not only can be used for education and study for clinical practice, but also could be used for simulation practice and nursing core skill.

\section{REFERENCES}

1. Tso C, Currie GM, Gilmore D, Kiat H. Electrocardiography: a technologist's guide to interpretation. Journal of Nuclear Medicine Technology. 2015;43(4):247-252.

https://doi.org/10.2967/jnmt.115.163501

2. Taggar JS, Coleman T, Lewis S, Jones M. Screening for atrial fibrillation-a cross-sectional survey of healthcare professionals in primary care. Plos One. 2016;11(4):e0152086.

https://doi.org/10.1371/journal.pone.0152086

3. Drew BJ, Ide B, Sparacino PS. Accuracy of bedside electrocardiographic monitoring: a report on current practices of critical care nurses. Heart \& Lung: The Journal of Critical Care. 1991; 20(6):597-607.

4. Kang JH, Suh IS, Kim JY. Intensive care unit nurses' knowledge and nursing practices regarding bedside electrocardiograph monitoring. The Journal of Korean Academic Society of Nursing Education. 2014;20(1):60-70. https://doi.org/10.5977/jkasne.2014.20.1.60

5. Korean Nurses Association. Learning objective of nursing [Internet]. Seoul: Korean Nurses Association; 2017 [cited 2019 October 25]. Available from:

http://www.kan.or.kr/kor/sp_library/sp_library02.php?mo $\mathrm{de}=$ view\&number $=5533 \& b \_$name$=$nurse_data\&page $=1$.

6. Kim JH, Bae HJ, Jung SY. Status of long-term estimation and supply of nurse. Journal of the Korean Data Analysis Society. 2017;19(2):1083-1097.

7. Lewis SL, Dirksen SR, Heitkemper MM, Bucher L. Medicalsurgical nursing. 9th ed. Shin GR, Kim OS, Kwang YH. Kim NC, Kim YG, Kim YJ, et al., translator. Seoul: Hyunmoonsa; 2019. p. 858-887.

8. Lynn-Mchale Wiegand DJ, Carlson KK. AACN Procedure Manual for Critical Care Volume 2. 6th ed. Korean Association of Critical Care Nurses, translator. Seoul: Elsevier Korea; 2014. p. 3-75.

9. Korean Association of Cardio Pulmonary Resuscitation, editors. Provider manual of Korea advanced life support (KALS). Seoul: Koonja; 2012. p. 23-107.

10. Robert JH. Basic dysrhythmias: interpretation \& management. 3rd ed. Cheon SJ, Kim JJ, lee YJ, Wang YJ, Song RY, translator. 
Seoul: Hyunmoonsa; 2010. p. 2-324.

11. Tadafumi D, Tetsurou S. Vividly clear guide of electrocardiography. 6th ed. Lee MH, translator. Seoul: Shinheung Medscience; 2010. p. 7-182.

12. Dubin D. Handbook of rapid interpretation of EKG's. 6th ed. Kim YH, Kim YH, Kim JY, Kim J, Kim JS, Na KH, et al., translator. Seoul: Koonja; 2008. p. 1-353.

13. Heinich R, Molenda M, Russell JD, Smaldino SE. Instructional media and technologies for learning. 7th ed. New Jersey: Prentice Hall; 2002. p. 3-350.

14. Smaldino SE, Lowther DL, Russell JD. Instructional technology and media for learning. 10th. ed. Lee MJ, Kwon HY, Kim DH, translator. Seoul: Academy Press; 2011. p. 80-115.

15. Yeom GJ, Kim IO. Development and effects of supplementary material about electronic fetal monitoring for nursing students. Korean Journal of Women Health Nursing. 2016;22(1):21-29. https://doi.org/10.4069/kjwhn.2016.22.1.21

16. Hazinski MF, Nolan JP, Billi JE, Böttiger BW, Bossaert L, de Caen AR, et al. Part 1: executive summary: 2010 international consensus on cardiopulmonary resuscitation a circulation and emergency cardiovascular care science with treatment recommendations. The Journal of the European Resuscitation Coun- cil. 2010;81(1):e1-e25.

https://doi.org/10.1016/j.resuscitation.2010.08.002

17. Keller JM. Motivational design for learning and performance: The arcs model approach. New York: Springer; 2010. p. 43-74.

18. Lee EO, Lim NY, Park, HA, Lee IS, Kim GI, Bae JE, et al. Nursing research and statistical analysis. Paju: Soomoonsa; 2009. p. 205.

19. Jang JY, Lee YJ, Park CB, Shin SD, Lee EJ, Song KJ. Diagnostic test performance characteristics of st-segment elevation myocardial infarction by level 1 emergency medical technicians before vs after an ECG education program. Journal of the Korean Society of Emergency Medicine. 2010;21(5):539-545.

20. Feltz DL. Self-confidence and sports performance. Exercise and Sport Sciences Reviews. 1998;16:423-457.

21. Davies A, Macleod R, Bennett-Britton I, McElnay P, Bakhbakhi $\mathrm{D}$, Sansom J. E-learning and near-peer teaching in electrocardiogram education: A randomized trial. The Clinical Teacher. 2016;13(3):227-230. https://doi.org/10.1111/tct.12421.

22. Lee HY, Lim HS, Kim MY. The clinical practice of newly graduated nurses who are resigned. Journal of Qualitative Research. 2011;12(1):36-48. 